ISSN: 2600-5859

\title{
Conflictos laborales en las empresas comerciales e industriales en el Ecuador
}

\section{Labor conflicts in commercial and industrial companies in Ecuador}

María del Carmen Ibarra Chango. ${ }^{1}$, Mónica del Pilar Vallejo Villalva. ${ }^{2}$ \& Iván Patricio Arias González. ${ }^{3}$

Recibido: 11-12-2019 / Revisado: 28-12-2019 / Aceptado: 05-01-2020 / Publicado: 07-02-2020

\begin{abstract}
.
DOI: https://doi.org/10.33262/concienciadigital.v3i1.1.1151

In order to have a broad vision on labor disputes, it was necessary to conduct research in two companies that demonstrated problems in its operation, research carried out at the production plant of wooden furniture "El Laurel" and the food marketer "La Enough ", the same ones that had more than fifty employees among office workers, service personnel, operators and workers, which are located in the city of Riobamba, province of Chimborazo, Republic of Ecuador. To obtain all kinds of information in labor relations, a work schedule and a questionnaire were prepared to separate the types of conflicts that were called "Conflicts between Employers", "Conflicts between Employers and Workers" and "Conflicts among the Workers", as José Dávalos selects them in his book. From all the information collected, it was necessary to structure the Problem Tree, an instrument used in Strategic Planning and from this the Objective Tree could be prepared, which clearly and in detail visualized the conflicts existing in the two companies of our investigation, whose result gave us that there were a series of legal infractions, violating the Companies Law and the Labor, Civil and Criminal Codes, before which legal and administrative advice was provided, and of this In this way, it was possible to legalize the companies, establish norms and fundamentally socialize certain mandates to correct the behavior of all the members of the companies in order to seek their harmony and consequently the stability and organizational development.

\footnotetext{
${ }^{1}$ Universidad Nacional de Chimborazo, Facultad de Ciencias Políticas y Administrativas, Carrera de Contabilidad y Auditoría, monica.vallejo@unach.edu.ec

${ }^{2}$ Universidad Nacional de Chimborazo, Facultad de Ciencias Políticas y Administrativas, Carrera de Contabilidad y Auditoría monica.vallejo@unach.edu.ec

${ }^{3}$ Universidad Nacional de Chimborazo, Facultad de Ciencias Políticas y Administrativas, Carrera de Contabilidad y Auditoría ivan.arias@unach,edu,ec
} 
Key Words Labor Conflict, Conflict between Employers, between Employers and Workers, Laws, Codes, Regulations, Problem Tree, Objective Tree

\section{Resumen}

Con el objeto de tener una visión amplia sobre los conflictos laborales, fue necesario realizar investigaciones en dos empresas que demostraban tener problemas en su funcionamiento, investigación realizada en la planta de producción de muebles de madera "El Laurel" y la comercializadora de alimentos "La Basta", las mismas que contaban con más de cincuenta empleados entre oficinistas, personal de servicio, operadores y obreros, las cuales se encuentran ubicadas en la ciudad de Riobamba, provincia de Chimborazo, república del Ecuador. Para obtener todo tipo de información en las relaciones laborales, se preparó un cronograma de trabajo y un cuestionario a fin de separar los tipos de conflictos que se los denominó "Conflictos entre los Empleadores", "Conflictos entre los Empleadores y Trabajadores" y "Conflictos entre los Trabajadores", como así los selecciona José Dávalos en su libro. De toda la información recopilada, fue necesario estructurar el Árbol de Problemas, un instrumento utilizado en Planificación estratégica y de éste se pudo elaborar el Árbol de Objetivos, con lo cual se visualizó con claridad y en detalle los conflictos existentes en las dos empresas de nuestra investigación, cuyo resultado nos dio que existían una serie de infracciones de carácter legal, violando la Ley de Compañías y los Códigos de Trabajo, Civil y Penal, ante lo cual se procedió a la prestación de asesoramiento de carácter Legal y Administrativo, y de esta manera, se logró legalizar las empresas, establecer normas y fundamentalmente socializar ciertos mandatos para corregir el comportamiento de todos los miembros de las empresas con la finalidad de buscar su armonía y consecuentemente la estabilidad, desarrollo organizacional y un ambiente de control adecuado

Palabras clave: Conflicto Laboral, Conflicto entre Empleadores, entre Empleadores y Trabajadores, Leyes, Códigos, Reglamentos, Árbol de Problemas, Árbol de Objetivos

\section{Introducción.}

En todos los países del mundo existen conflictos laborales, conflictos ocasionados por la disconformidad en el convivir entre seres humanos, peor aún, al interior de una empresa, donde se presentan intereses especialmente de carácter económico.

La mayoría de los conflictos entre los propietarios de las empresas, son ocasionados por el mal manejo de los recursos humanos y económicos.

La inconformidad del ser humano de todo tipo de intereses, causan daño no solamente entre las personas, sino directamente a las organizaciones empresariales, debido a que éstas no pueden crecer o desarrollarse con normalidad, por lo contrario, se crea estancamientos de toda índole. Por lo expuesto y con la finalidad de lograr armonía y desarrollo en todos los ámbitos, fue necesario buscar soluciones de carácter legal y administrativo.

\section{Conflicto Laboral.}

"La palabra conflicto proviene del latín conflictus, que significa combate, lucha, pelea. Desde el punto de vista jurídico, se utilizan como expresiones sinónimas diferencia, 
controversia, colisión, litigio, etcétera; todas ellas tienen invariablemente la connotación de pretensión resistida, de oposición de intereses. La Constitución mexicana establece desde el año de 1917, que "Las diferencias o los conflictos entre el capital y el trabajo, se sujetarán a la decisión de una Junta de Conciliación y Arbitraje". El significado y diferencia entre ambos vocablos fue objeto de acaloradas discusiones doctrinales, que hoy día están superadas. Suelen también referirse algunas leyes a "los juicios" como sinónimo de conflictos. En todo caso, no hay que confundir el conflicto, como fenómeno social, con el conjunto de actos procesales que constituyen la vía para solucionar dicho altercado. En sentido amplio se define a los conflictos laborales como "las fricciones que pueden producirse en las relaciones de trabajo". Un concepto tan amplio que abarca lo mismo una huelga general, que la inconformidad de un trabajador por un pequeño e indebido descuento salarial. Los conflictos de trabajo, en sentido estricto, "son las diferencias que pueden suscitarse entre trabajadores y patrones, sólo entre aquéllos o sólo entre éstos, como consecuencia o con motivo del nacimiento, modificación o cumplimiento de las relaciones individuales o colectivas de trabajo" (UNAM, 1980, pág. 216)

Quienes son parte de una empresa sea comercial, industrial o de servicio, están conscientes, que el origen de todo conflicto, es el resultado de que toda persona percibe en el espacio cierta inconformidad en el desarrollo de sus actividades, todo debido a que siempre espera preferencias sea en la ocupación de los puestos de trabajo de mayor relevancia o remuneraciones sobre los demás, así como el tratamiento entre el empleador y sus compañeros, además de que por su naturaleza, el ser humano es inconformista, por lo cual uno de los niveles relacionados a la necesidad de seguridad es la que actúa al momento de formarse un conflicto. El conflicto además se origina porque existen diferencias en la percepción y definición de la situación, necesidades e intereses de las partes involucradas, valores y creencias que defienden la propia posición y que pueden estar en desacuerdo con las otras partes.

Debemos tener presente que todo conflicto atrae agresiones de unos a otros, las agresiones, las mismas que debemos comprender que son ataques producto de la práctica o del hábito de ser agresivos, siendo una conducta hostil o destructiva cuya finalidad es provocar un daño a otro. Por lo regular es provocada por personas violentas que se manifiestan en formas muy diversas, tomando en consideración que la violencia es la utilización de la fuerza física o del poder contra uno mismo o contra otros, de modo que este acto cause daños físicos, daños psicológicos o privaciones. Existen muchos tipos de violencia que son practicados en los conflictos, como el bullying, violencia colectiva, violencia física, verbal, económica, negligencia entre otras.

Los conflictos laborales son aquellos problemas que suelen presentarse en el lugar del trabajo y que afectan a las actividades de la empresa ya que el ambiente se torna desagradable, los conflictos como nos expresamos anteriormente, pueden ser diferencias que existen entre los empleadores y trabajadores de una empresa.

"Según José Dávalos (2000 pág. 217) Los conflictos laborales se clasifican en: a) En razón de los sujetos involucrados genéricamente, entre trabajadores y patrones y de conformidad a nuestro criterio, por lo general, estos conflictos dentro del área laboral pueden clasificarse: a) entre trabajadores y patronos, b) entre trabajadores y c) entre patrones". 
Podemos manifestar que los conflictos entre trabajadores y patronos, son comunes dentro de las empresas ya que por regular éstos se presentan por problemas en el trabajo o de carácter económico.

Se ha podido comprobar en nuestra investigación, que estos tipos de conflictos por lo regular se deben, cuando los patronos exigen por parte del trabajador mayor rendimiento en sus actividades, cuando los trabajadores no están de acuerdo con los despidos intempestivos y especialmente cuando se incumple con los derechos económicos que por ley tienen los trabajadores.

"Diferentes tipos de conflictos: a) Conflictos entre patrones. Estos conflictos son muy escasos por cuanto, quienes dirigen una empresa suelen compartir ideas entre ellos, únicamente puede darse algún caso, a causa de acciones indebidas por parte de los trabajadores, es así que algunos de estos casos son resueltos casi inmediatamente. b) En función de la naturaleza del conflicto "La doctrina, la jurisprudencia y la ley consideran que atendiendo a la naturaleza o contenido del conflicto, estos pueden ser de orden jurídico o de orden económico" el conflicto económico que hace referencia a la modificación de las condiciones laborales, esto puede ser referente al salario, reducción de personal o diferentes actividades en las que los empleados sientan que son perjudicados. c) Por el tipo de interés que se afecta. Esta clasificación está referida a la jerarquía del interés que se ve afectado con el conflicto, sin que se trate simplemente de una afectación numérica, es decir no responde al número de contendientes. Dentro de este nivel tenemos una sub-clasificación que es: Los conflictos individuales los que afectan los intereses de uno o varios trabajadores. Los conflictos colectivos que afectan los intereses de grupos de sindicatos de los trabajadores. Según las investigadoras un conflicto laboral por más pequeño que sea afecta el área de trabajo, ya que no se logra un ambiente agradable y un trabajo en equipo por parte de quienes conforman la empresa. Dentro de las empresas se debe dar un seguimiento a los conflictos existentes para prevenir y lo posible disminuir este problema que afecta al área laboral”. (Pacheco Mena \& Zapata López, 2014)

Para poder visualizar un poco sobre los conflictos laborales, se tuvo que realizar diagnósticos (investigaciones) en dos tipos diferentes de empresas, una industrial de muebles para el hogar "El Laurel" y otra comercial de supermercado "La Basta" en la ciudad de Riobamba, las mimas que mantenían una serie de conflictos laborales que afectaban a su desarrollo, para lo cual, se estructuró el Árbol de Problemas que consistió en procesar un diagnóstico participativo y que consistió en desarrollar los siguientes pasos:

Identificar el problema central en base a las preguntas ¿Qué sabemos?, ¿Qué más necesitamos saber?, preguntas que se desarrollaron durante la investigación y poder así establecer concretamente el problema central.

Plan de diagnóstico, para llevar a cabo nuestro estudio que permita obtener resultados concretos y reales, fue necesario instalar un pequeño plan que se basó en establecer ¿Quién va a recolectar la información?, ¿Qué información se requiere?, ¿Dónde se recopila la información?, ¿Cómo?, eventualmente ¿Con qué? y ¿Cuándo?. Para recoger la información en este proceso fue necesario, 
la participación de los propietarios de las empresas y algunos trabajadores que voluntariamente colaboraron.

Después de haber cumplido con los procesos anteriores, se procedió a socializar los resultados del diagnóstico, no solo porque se consideró que era cuestión de principio, sino como un mecanismo adecuado para que tanto los propietarios, como los trabajadores de las dos empresas, lograran una conciliación pacífica y normalización de sus actividades, evitando así la quiebra de las empresas y pérdida de trabajo.

\section{Metodología Árbol de Problemas}

De esta actividad, se procedió a estructurar el Árbol de Problemas, el mismo que nos demuestra los estados negativos de la realidad y que está conformado por varios componentes, considerando ante todo, que todo problema tiene solución sean éstos de carácter social, económico, político, religioso, es decir la modificación de determinados comportamientos.

No olvidemos que todo problema es algo que se quiere modificar, esto depende de los intereses, del enfoque analítico y de la especialización de quienes lo formulan o perciben.

Si se considera importante afrontar un problema cuya escala desborda el ámbito geográfico y social del ejercicio de buscar una solución, se destaca ese problema para un tratamiento posterior y se establece en este caso de conflictos laborales las correspondientes demandas judiciales.

En el proceso de la estructuración del árbol de problemas, se inicia, conociendo ¿Cuáles son las causas del problema?, las mismas que son factores sociales, tecnológicos, económicos o legales, que solos o con otros, generan un problema.

Pero es necesario conocer también ¿que son los descriptores?, que no son causas sino síntomas del problema central. Los descriptores fundamentan la existencia del problema central, son indicadores cualitativos y cuantitativos que precisan el problema central y sirven para verificar los resultados de las operaciones con las que se pretende enfrentarlos, por eso no se puede confundir los descriptores con las causas del problema, por cuanto los primeros se refieren a los síntomas, las segundas nos indican las razones de los problemas existentes.

Las causas pueden identificarse como directas, que explican o condicionan de manera directa a los descriptores del problema central, causas indirectas, explican y condicionan a las causas directas, es decir que tienen un alcance medio en la descripción de los problemas y causas estructurales, que indican los problemas de orden social, político, económico, jurídico, etc. y que presentan como normas básicas de funcionamiento del sistema.

A continuación se presenta en el cuadro No 1 el árbol de problemas en el ámbito laboral estructurado de conformidad a los problemas existentes en las dos empresas de nuestra investigación. 
Gráfico No 1. Árbol de Problema

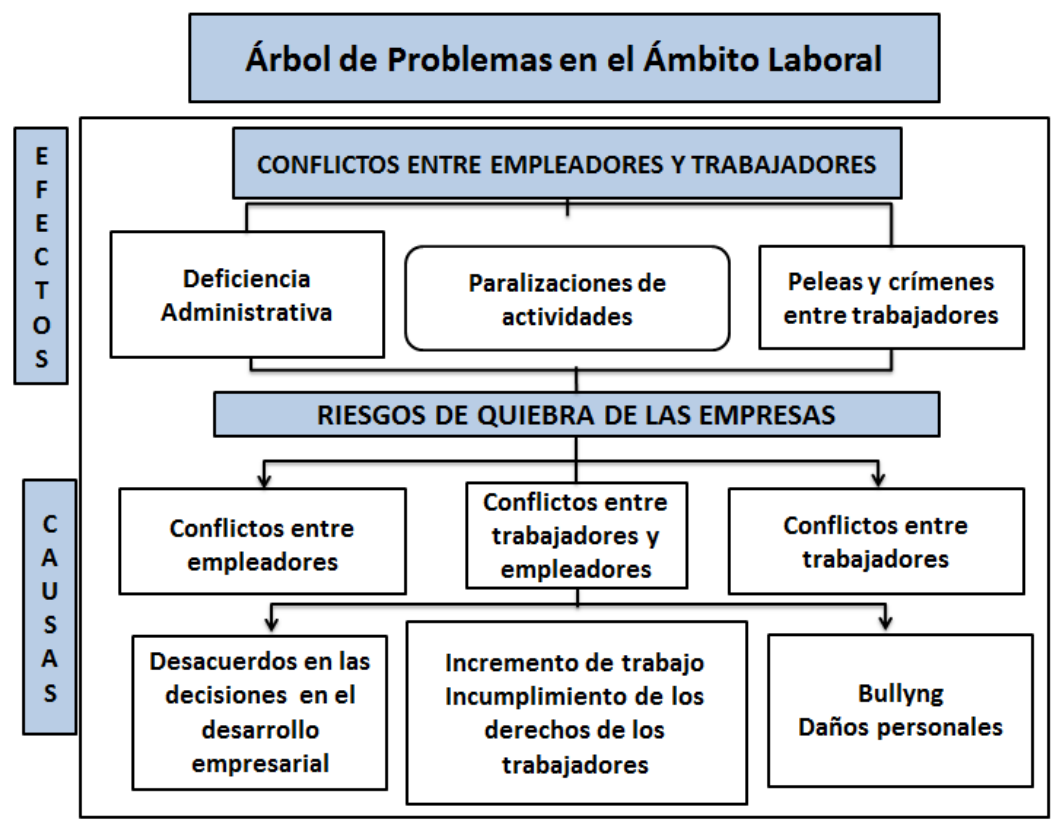

Elaborado por: Autores

El Árbol de Problemas, nos facilitó en poder conocer las causas y efectos por las cuales se ocasionaban los diferentes conflictos que a continuación se detalla:

Conflictos entre empleadores, todo surgía debido a que entre propietarios o accionistas sin representar a las empresas ni consultar a sus socios, realizaban cambios de personal, incremento en las remuneraciones, disponían de los recursos financieros indiscriminadamente, entre otras causas, cuyos efectos daban como resultados una mala administración de los recursos humanos y administrativos en general.

Conflictos existentes entre trabajadores y empleadores, las causas detectadas fueron debido a que sin ninguna programación de trabajo, se incrementaban actividades, que en muchos de los casos los empleados en general, no podían cumplirlos, no se reconocían incentivos como la antigüedad entre los trabajadores, los pagos se los realizaban atrasados, habiendo disponibilidad de recursos financieros en caja, así como retrasos en el pago de obligaciones con el Instituto Ecuatoriano de Seguridad Social (IESS) y el Servicio de Rentas Internas (SRI), por lo que los servidores no podían obtener sus prestaciones toda vez que requerían, como créditos o asistencia médica, se imposibilitaba el derecho de sus vacaciones anuales, debido a que no existían reemplazos para cumplir con sus obligaciones, motivos éstos, que creaban inconformidad por parte de los empleados o trabajadores, demostrando insatisfacciones ante los empleadores. 
Conflictos entre los trabajadores, se debía a la falta de una selección adecuada de personal, acarreando gente que no tenía principios de respeto entre sus compañeros, practicando el Bullyng entre los más fuertes contra los más débiles, ocasionándose en muchas ocasiones peleas entre ellos, corriendo el riesgo de ocasionarse crímenes al interior de las organizaciones empresariales.

\section{Árbol de Objetivos}

Con la finalidad de buscar soluciones a los conflictos existentes en las dos empresas la comercial y la industrial de la ciudad de Riobamba y con la finalidad de tener una visión clara del problema, se estructuró un Árbol de Objetivos en el Ámbito Laboral, árbol que se presenta en el grafico No. 2 .

Gráfico No 2. Árbol de Objetivos

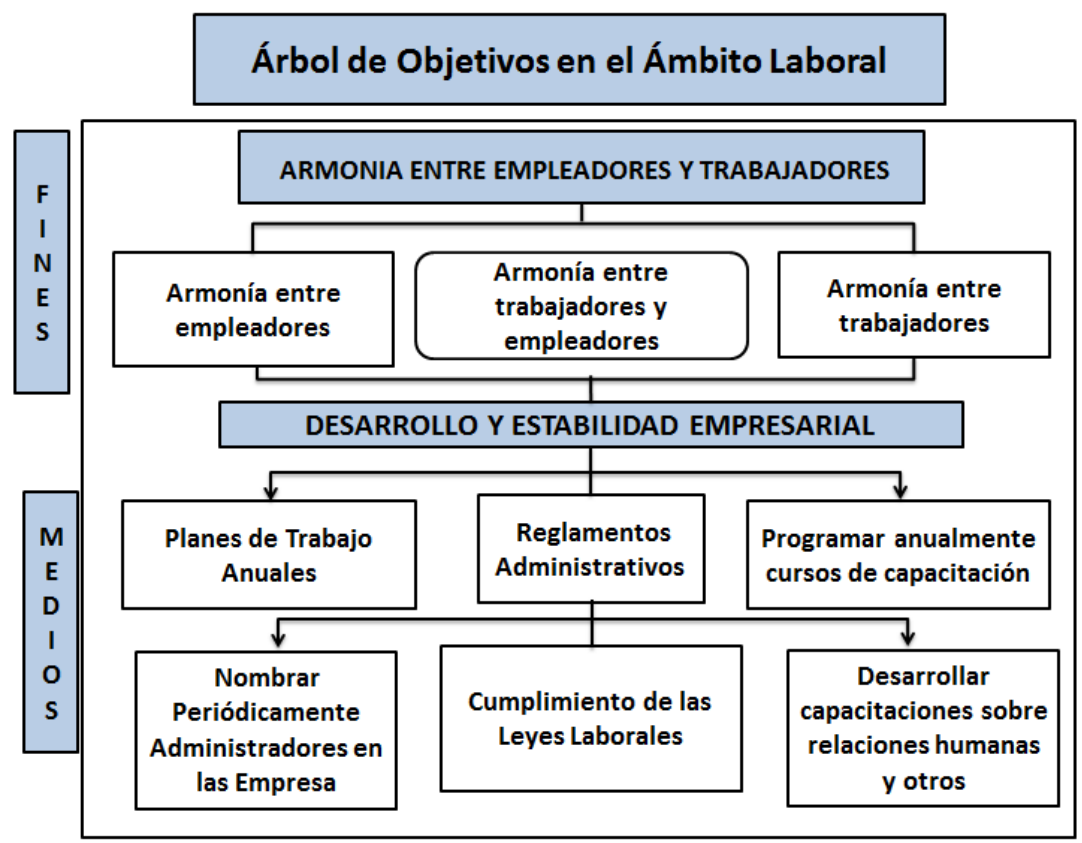

Elaborado por: Autores

Se pudo demostrar en el árbol de objetivos, que para dar soluciones a los diferentes conflictos laborables existentes en las empresas, se utilizaron los medios necesarios para atacar a las causas y efectos; logrado de esta manera, los fines, que no son otra cosa que armonizar en todos los ámbitos para el desarrollo empresarial tanto en el orden legal, como en el orden administrativo.

\section{Solución de Conflictos entre Empleadores}


Mediante el correspondiente asesoramiento legal y administrativo entregado a los propietarios de las indicadas empresas, fue necesario que conozcan y den cumplimiento a la Ley de Compañías a fin de normalizar sus actividades para lo cual fue necesario que pongan en práctica algunos artículos tales como: “Art. 6.- de la Ley de Compañías que dice: "Toda compañía nacional o extranjera que negociare o contrajera obligaciones en el Ecuador deberá tener en la República un apoderado o representante que pueda contestar las demandas y cumplir las obligaciones respectivas"; asimismo, en el Art. 9.- Las compañías u otras personas jurídicas que contrajeran en el Ecuador obligaciones que deban cumplirse en la República y no tuvieren quien las represente, serán consideradas como el deudor que se oculta y podrán ser representadas por un curador dativo" Estado Ecuatoriano Registro Oficial, (2017), por lo que se procedió a su legalización, por cuanto estas organizaciones venían operando sin tener los Estatutos que les permita normalizar sus actividades.

Por otra parte, se fue fortaleciendo a las compañías, cumpliendo con los mandatos establecidos en el Código Civil según los: "Art. 11.- El que contratare por una compañía que no hubiere sido legalmente constituida, no puede sustraerse, por esta razón, al cumplimiento de sus obligaciones. Art. 13.- Designado el administrador que tenga la representación legal y presentada la garantía, si se la exigiere, inscribirá su nombramiento, con la razón de su aceptación, en el Registro Mercantil, dentro de los treinta días posteriores a su designación, sin necesidad de la publicación exigida para los poderes ni de la fijación del extracto. La fecha de la inscripción del nombramiento será la del comienzo de sus funciones. Sin embargo, la falta de inscripción no podrá oponerse a terceros, por quien hubiere obrado en calidad de administrador. En el contrato social se estipulará el plazo para la duración del cargo de administrador que, con excepción de lo que se refiere a las compañías en nombre colectivo y en comandita simple, no podrá exceder de cinco años, sin perjuicio de que el administrador pueda ser indefinidamente reelegido o removido por las causas legales" Estado Ecuatoriano Registro Oficial (2017).

Asimismo, fue necesario dar a conocer a los Administradores de las empresas, ciertas disposiciones legales establecidas en el mismo Código tales como: "Art. 30.- Los que contrataren a nombre de compañías que no se hubieren establecido legalmente serán solidariamente responsables de todos los perjuicios que por la nulidad de los contratos se causen a los interesados y, además, serán castigados con arreglo al Código Penal. La falta de escritura pública no puede oponerse a terceros que hayan contratado de buena fe con una compañía notoriamente conocida. En igual responsabilidad incurrirán los que a nombre de una compañía, aun legalmente constituida, hicieren negociaciones distintas a las de su objeto y empresa, según este determinado en sus estatutos" Estado Ecuatoriano Registro Oficial ( 2017).

Todos estas disposiciones, fueron debidamente trasmitidas a los accionistas y con su pleno conocimiento, se fue mejorando el sistema organizacional de cada una de las empresas objeto de nuestra investigación, además de que conjuntamente con los empresarios, empleados y representantes de los trabajadores, se pudo estructurar los Planes de Trabajo para el período presente, que administrativamente consistió en determinar los antecedentes de los conflictos existentes al interior de las empresas, plantear objetivos que permita el desarrollo empresarial, implementar reglamentos internos de carácter administrativo y operativo, priorizar las necesidades 
de recursos económicos, humano, bienes, materiales y servicios, así como estrategias para mejorar la productividad y ventas.

\section{Soluciones a los Conflictos existentes entre Trabajadores y Empleadores}

Asimismo, con nuestra intervención, se socializó algunas disposiciones legales de los principales artículos establecidos en el Código de Trabajo en vigencia en el Ecuador y que a continuación se los detalla:

¿Qué nos manifiesta el Código de Trabajo?: “Art. 1.- Ámbito de este Código.- Los preceptos de este Código regulan las relaciones entre empleadores y trabajadores y se aplican a las diversas modalidades y condiciones de trabajo. Las normas relativas al trabajo contenidas en leyes especiales o en convenios internacionales ratificados por el Ecuador, serán aplicadas en los casos específicos a las que ellas se refieren"... con respecto a que no se reconocía derechos a los trabajadores nos manifiesta el "Art. 4.- Irrenunciabilidad de derechos.- Los derechos del trabajador son irrenunciables. Será nula toda estipulación en contrario"..."Art. 7.- Aplicación favorable al trabajador.- En caso de duda sobre el alcance de las disposiciones legales, reglamentarias o contractuales en materia laboral, los funcionarios judiciales y administrativos las aplicarán en el sentido más favorable a los trabajadores"." (Registro Oficial Estado Ecuatoriano, 2012).

Una de las observaciones detectadas en los procesos de contratación por parte de los empleadores, fue que los contratos de trabajo no cumplían con ciertos detalles de orden administrativo, que por estas causas existían conflictos entre empleadores y trabajadores, luego de conocer los aspectos legales se presenta en detalle las cláusulas del Contrato de Trabajo que causan conflictos.

Se recomendó, que todo contrato de trabajo sea escrito, "Art. 18.- Contrato escrito.- El contrato escrito puede celebrarse por instrumento público o por instrumento privado. Constará en un libro especial y se conferirá copia, en cualquier tiempo, a la persona que lo solicitare...Art. 21.- Requisitos del contrato escrito.- En el contrato escrito deberán consignarse, necesariamente, cláusulas referentes a: 1. La clase o clases de trabajo objeto del contrato; 2. La manera como ha de ejecutarse: si por unidades de tiempo, por unidades de obra, por tarea, etc.; 3. La cuantía y forma de pago de la remuneración; 4. Tiempo de duración del contrato; 5. Lugar en que debe ejecutarse la obra o el trabajo; y, 6. La declaración de si se establecen o no sanciones, y en caso de establecerse la forma de determinarlas y las garantías para su efectividad". " (Registro Oficial Estado Ecuatoriano, 2012).

Anotando también, que: "Art. 40.- Derechos exclusivos del trabajador.- El empleador no podrá hacer efectivas las obligaciones contraídas por el trabajador en los contratos que, debiendo haber sido celebrados por escrito, no lo hubieren sido; pero el trabajador sí podrá hacer valer los derechos emanados de tales contratos. En general, todo motivo de nulidad que afecte a un contrato de trabajo sólo podrá ser alegado por el trabajador. Art. 41.- Responsabilidad solidaria de empleadores.Cuando el trabajo se realice para dos o más empleadores interesados en la misma empresa, como 
condueños, socios o copartícipes, ellos serán solidariamente responsables de toda obligación para con el trabajador". Registro Oficial Estado Ecuatoriano, (2012)

Con este motivo, se dio a conocer que los contratos de trabajo escritos han sido preparados por el Ministerio del Trabajo que a más del formato, se debe tomar en cuenta aspectos de vital importancia para las partes tanto para los trabajadores, como para los empleadores y que se describe a continuación:

Habiendo cumplido con el proceso de selección de personal, acto seguido es legalizar el correspondiente contrato de trabajo, ante lo cual se recomendó que es necesario tomar muy en cuenta a más de los aspectos legales que rige el Contrato de Trabajo, las cláusulas referentes al OBJETO DEL CONTRATO y HORARIO DE TRABAJO.

Con respecto al Objeto del Contrato en el documento emitido por el Ministerio del Trabajo, es demasiado lacónico, debido a que es necesario describir con claridad las funciones o actividades y responsabilidades que se compromete el trabajador o empleado a cumplir en la empresa, para lo cual dimos ejemplos de ello:

"El Contrato de Trabajo de un empleado que deba cumplir funciones de Vendedor del Supermercado "La Basta" son: a) Atención al cliente, b) Ordenamiento de mercadería, c) Demostraciones de productos, sus contenidos y utilidades entre otras, d)Entrevistas sobre protocolo de exhibición y seguridad de productos, f) Manejo de Caja (responsabilidad pecuniaria), g) Resolución de problemas o reclamos de clientes, h) Uso adecuado del uniforme, i) Mantener limpias las vitrinas o estanterías y piso en general, j) Cuidado de los bienes de la empresa de los delincuentes, k) Controlar los registros de videos de la tienda, 1)Otras actividades relacionadas a sus funciones y responsabilidades" Oficina Nacional de Personal Estado Ecuatoriano ( 1999)

Con respecto al horario de trabajo, se debe manifestar que debido a las funciones de atención al público, será rotativo de ocho horas diarias continuas de acuerdo al servicio del almacén.

"La Descripción de Funciones de Operadores de Maquinaria de la industria de muebles "El Laurel" es: a) Preparar y poner a punto el puesto de trabajo, herramientas, maquinaria auxiliar y máquinas necesarias para llevar a cabo las operaciones de mecanizado y acabado de elementos de carpintería y mueble. b) Realizar e interpretar documentos técnicos, notas de madera, bocetos, croquis y planos sobre los trabajos que debe realizar. c) Efectuar operaciones de trazado, corte y mecanizado en madera y sus derivados utilizando los procedimientos más adecuados para cada material. d) Realizar uniones en madera y derivados siguiendo criterios de resistencia, economía y funcionalidad. e) Realizar operaciones de acabados, a mano y a máquina, en una atmósfera limpia, preparando previamente las superficies así como los equipos y materiales para que actúen en óptimas condiciones de calidad y seguridad. f) Realizar el montaje y ajuste de muebles y elementos de carpintería mediante herramientas portátiles consiguiendo un perfecto encaje, enrase o deslizamiento de las partes móviles. g) Realizar el embalaje de muebles y elementos de 
carpintería, de forma manual o automática, cumpliendo el programa establecido así como las normas de seguridad y protección medioambiental. h) Participar en el transporte de productos, equipos y elementos auxiliares, siguiendo las normas establecidas en la empresa y en el sector, para conseguir un óptimo abastecimiento de materias y útiles. i) Colaborar en el montaje e instalación de elementos de carpintería y mueble (incluidos modulares), en cercos, obras y espacios, en condiciones de calidad, no dañando los productos, ni los elementos arquitectónicos donde van fijados. j) Afilar y asentar el corte en herramientas manuales de corte libre y realizar el mantenimiento de máquinas y útiles de afilar y asentar. k) Colaborar en las operaciones de instalación de parquet, tarima o frisos, aplicando pastas de nivelación, lijando superficies y ayudando en los procesos de ajustes y acabados. 1) Trabajar solo o como parte de un equipo, siguiendo los principios de orden, limpieza, puntualidad, responsabilidad y coordinación. m) Cumplir las normas de seguridad en el puesto de trabajo anticipándose y previniendo los posibles riesgos personales, en los productos, en maquinaria o en las instalaciones. n) Actuar con el máximo respeto hacia el medio ambiente, así como tener un trato correcto y educado con los compañeros, encargados y clientes”. Estado Ecuatoriano Consejería de Educación ( 2008)

En cuanto al horario de trabajo normalmente es de ocho horas de las 8 am a las $16 \mathrm{pm}$, toda vez que se requiera sus servicios el empleador se comprometió a pagar el correspondiente sobre tiempo de acuerdo a la Ley.

Para una buena armonía empresarial es necesario recordar que existen obligaciones tanto para los empleadores, como para los trabajadores de conformidad al indicado Código de Trabajo: "Capítulo IV De las obligaciones del empleador y del trabajador Art. 42.Obligaciones del empleador.- Son obligaciones del empleador: 1. Pagar las cantidades que correspondan al trabajador, en los términos del contrato y de acuerdo con las disposiciones de este Código; 2. Instalar las fábricas, talleres, oficinas y demás lugares de trabajo, sujetándose a las medidas de prevención, seguridad e higiene del trabajo y demás disposiciones legales y reglamentarias, tomando en consideración, además, las normas que precautelan el adecuado desplazamiento de las personas con discapacidad; 3. Indemnizar a los trabajadores por los accidentes que sufrieren en el trabajo y por las enfermedades profesionales, con la salvedad prevista en el Art. 38 de este Código; 8. Proporcionar oportunamente a los trabajadores los útiles, instrumentos y materiales necesarios para la ejecución del trabajo, en condiciones adecuadas para que éste sea realizado; 9. Conceder a los trabajadores el tiempo necesario para el ejercicio del sufragio en las elecciones populares establecidas por la ley, siempre que dicho tiempo no exceda de cuatro horas, así como el necesario para ser atendidos por los facultativos de la Dirección del Seguro General de Salud Individual y Familiar del Instituto Ecuatoriano de Seguridad Social, o para satisfacer requerimientos o notificaciones judiciales. Tales permisos se concederán sin reducción de las remuneraciones; 10 . Conceder a las trabajadoras víctimas de violencia de género, el tiempo necesario para tramitar y acceder a las medidas administrativas o judiciales dictadas por autoridad competente, el mismo que no afectará su derecho a recibir su remuneración completa, ni sus vacaciones" "Registro Oficial Estado Ecuatoriano ( 2012). 
Por otra parte los empleadores deben mantener presente ciertas prohibiciones como se determina en el Código de Trabajo "Art. 44.- Prohibiciones al empleador.- Prohíbese al empleador: a) Imponer multas que no se hallaren previstas en el respectivo reglamento interno, legalmente aprobado; b) Retener más del diez por ciento (10\%) de la remuneración por concepto de multas; c) Exigir al trabajador que compre sus artículos de consumo en tiendas o lugares determinados; d) Exigir o aceptar del trabajador dinero o especies como gratificación para que se le admita en el trabajo, o por cualquier otro motivo; e) Cobrar al trabajador interés, sea cual fuere, por las cantidades que le anticipe por cuenta de remuneración; entre otras." " (Registro Oficial Estado Ecuatoriano, 2012).

En cuanto al trabajador deberá mantener presente sobre las disposiciones establecidas en el mencionado Código. "Art. 45.- Son obligaciones del trabajador: a) Ejecutar el trabajo en los términos del contrato, con la intensidad, cuidado y esmero apropiados, en la forma, tiempo y lugar convenidos; b) Restituir al empleador los materiales no usados y conservar en buen estado los instrumentos y útiles de trabajo, no siendo responsable por el deterioro que origine el uso normal de esos objetos, ni del ocasionado por caso fortuito o fuerza mayor, ni del proveniente de mala calidad o defectuosa construcción; c) Trabajar, en casos de peligro o siniestro inminentes, por un tiempo mayor que el señalado para la jornada máxima y aún en los días de descanso, cuando peligren los intereses de sus compañeros o del empleador. En estos casos tendrá derecho al aumento de remuneración de acuerdo con la ley" " (Registro Oficial Estado Ecuatoriano, 2012).

En cuanto a los medios que se deben utilizar para evitar los conflictos existentes entre empleadores y trabajadores, fue necesario normar los horarios y distribución de tareas de cada uno de los trabajadores o empleados, reconocimiento e incentivos a los empleados de mayor antigüedad, cumplir oportunamente con los derechos establecidos en la ley y en lo referente a los conflictos existentes entre los trabajadores, se recomendó mantener reuniones que se permita mejorar sus relaciones de trabajo mediante el respeto de unos a otros, haciéndoles notar a cada uno de los integrantes que los daños ocasionados entre ellos pueden conducirles a la muerte y consecuentemente a la prisión.

La finalidad de todo este proceso, nos conllevó a lograr la armonía que debe existir entre empleadores y trabajadores y de esta manera desarrollar y estabilizar a la empresa en beneficio de todos.

Cuando se define que una de las causales que ocasionan conflictos puede ser la falta de conocimiento de la Leyes y Códigos que rigen en el Ecuador como la de Compañías, Penal y Trabajo; y, una Selección adecuada de Personal.

\section{Solución de Conflictos existentes entre los trabajadores}

"En el Código de trabajo en el Art. 45.- literales manifiestan: d) Observar buena conducta durante el trabajo; e) Cumplir las disposiciones del reglamento interno expedido en forma legal; f) Dar aviso al empleador cuando por causa justa faltare al trabajo; g) Comunicar al empleador o a su representante los peligros de daños materiales que amenacen la vida o los intereses de empleadores o trabajadores; h) Guardar escrupulosamente los secretos técnicos, 
comerciales o de fabricación de los productos a cuya elaboración concurra, directa o indirectamente, o de los que él tenga conocimiento por razón del trabajo que ejecuta; i) Sujetarse a las medidas preventivas e higiénicas que impongan las autoridades; y, j) Las demás establecidas en este Código. Art. 46.- Prohibiciones al trabajador.- Es prohibido al trabajador: a) Poner en peligro su propia seguridad, la de sus compañeros de trabajo o la de otras personas, así como de la de los establecimientos, talleres y lugares de trabajo; b) Tomar de la fábrica, taller, empresa o establecimiento, sin permiso del empleador, útiles de trabajo, materia prima o artículos elaborados; c) Presentarse al trabajo en estado de embriaguez o bajo la acción de estupefacientes; d) Portar armas durante las horas de trabajo, a no ser con permiso de la autoridad respectiva; e) Hacer colectas en el lugar de trabajo durante las horas de labor, salvo permiso del empleador; f) Usar los útiles y herramientas suministrados por el empleador en objetos distintos del trabajo a que están destinados; g) Hacer competencia al empleador en la elaboración o fabricación de los artículos de la empresa; $h$ ) Suspender el trabajo, salvo el caso de huelga; e) Abandonar el trabajo sin causa legal. j) El cometimiento de actos de acoso laboral hacia un compañero o compañera, hacia el empleador, hacia un superior jerárquico o hacia una persona subordinada en la empresa” Registro Oficial Estado Ecuatoriano (2012).

Toda vez que existen conflictos que ocasionan lesiones entre los trabajadores, es necesario socializar asimismo, algunos postulados del Código Orgánico Integral Penal, como advertencia a mejorar las relaciones humanas que debe existir entre los trabajadores y empleados. "Artículo 1.- Finalidad.- Este Código tiene como finalidad normar el poder punitivo del Estado, tipificar las infracciones penales, establecer el procedimiento para el juzgamiento de las personas con estricta observancia del debido proceso, promover la rehabilitación social de las personas sentenciadas y la reparación integral de las víctimas. Artículo 26.- Dolo.- Actúa con dolo la persona que tiene el designio de causar daño. Responde por delito preterintencional la persona que realiza una acción u omisión de la cual se produce un resultado más grave que aquel que quiso causar, y será sancionado con dos tercios de la pena. Artículo 27.- Culpa.Actúa con culpa la persona que infringe el deber objetivo de cuidado, que personalmente le corresponde, produciendo un resultado dañoso. Esta conducta es punible cuando se encuentra tipificada como infracción en este código. Artículo 28.- Omisión dolosa.- La omisión dolosa describe el comportamiento de una persona que, deliberadamente, prefiere no evitar un resultado material típico, cuando se encuentra en posición de garante. Se encuentra en posición de garante la persona que tiene una obligación legal o contractual de cuidado o custodia de la vida, salud, libertad e integridad personal del titular del bien jurídico y ha provocado o incrementado precedentemente un riesgo que resulte determinante en la afectación de un bien jurídico. Artículo 34.- Culpabilidad.- Para que una persona sea considerada responsable penalmente deberá ser imputable y actuar con conocimiento de la antijuridicidad de su conducta. Artículo 39.- Tentativa.- Tentativa es la ejecución que no logra consumarse o cuyo resultado no llega a verificarse por circunstancias ajenas a la voluntad del autor, a pesar de que de manera dolosa inicie la ejecución del tipo penal mediante actos idóneos conducentes de modo inequívoco a la realización de un delito. En este caso, la persona responderá por tentativa y la pena aplicable será de uno a dos tercios de la que le correspondería si el delito se habría consumado. Artículo 41.- Participación.- Las personas participan en la infracción como autores o cómplices. Las circunstancias o condiciones que limitan o agravan la responsabilidad penal de una autora, de un autor o cómplice no influyen en la situación jurídica de los demás 
partícipes en la infracción penal. Artículo 42.- Autores.- Responderán como autoras las personas que incurran en alguna de las siguientes modalidades: 1. Autoría directa: a) Quienes cometan la infracción de una manera directa e inmediata. b) Quienes no impidan o procuren impedir que se evite su ejecución teniendo el deber jurídico de hacerlo. 2. Autoría mediata: a) Quienes instiguen o aconsejen a otra persona para que cometa una infracción, cuando se demuestre que tal acción ha determinado su comisión. b) Quienes ordenen la comisión de la infracción valiéndose de otra u otras personas, imputables o no, mediante precio, dádiva, promesa, ofrecimiento, orden o cualquier otro medio fraudulento, directo o indirecto. c) Quienes, por violencia física, abuso de autoridad, amenaza u otro medio coercitivo, obliguen a un tercero a cometer la infracción, aunque no pueda calificarse como irresistible la fuerza empleada con dicho fin. d) Quienes ejerzan un poder de mando en la organización delictiva. 3. Coautoría: Quienes coadyuven a la ejecución, de un modo principal, practicando deliberada e intencionalmente algún acto sin el cual no habría podido perpetrarse la infracción. Artículo 43.- Cómplices.- Responderán como cómplices las personas que, en forma dolosa, faciliten o cooperen con actos secundarios, anteriores o simultáneos a la ejecución de una infracción penal, de tal forma que aun sin esos actos, la infracción se habría cometido. No cabe complicidad en las infracciones culposas. Si de las circunstancias de la infracción resulta que la persona acusada de complicidad, coopera en un acto menos grave que el cometido por la autora o el autor, la pena se aplicará solamente en razón del acto que pretendió ejecutar. El cómplice será sancionado con una pena equivalente de un tercio a la mitad de aquella prevista para la o el autor”.(Asamblea Nacional República del Ecuador, 2014)

\section{Resultados}

Consideramos que para diagnosticar los problemas existentes en una empresa, se debe utilizar los medios de la Planificación Estratégica, como es el Árbol de Problemas, que nos permite visualizar las causas y efectos que ocasionan los conflictos como en este caso laborales.

Siempre es necesario separar los conflictos de los propietarios o empleadores, debido a que éstos conllevan a determinar las causas de los conflictos que se presentan entre empleadores y trabajadores, así como puede repercutir en conflictos únicamente de los trabajadores, debido a que éstos por lo regular demuestran irrespeto entre sus compañeros o superiores al interior de las organizaciones empresariales.

Para solucionar todo tipo de conflictos al interior de las empresas, se debe diagnosticar, analizar y asesorar conjuntamente entre profesionales en Derecho y Administración, debido a que en estos casos, por lo regular, tienen que ver asuntos relacionados a las leyes, códigos y reglamentaciones conjuntamente con la gestión administrativa.

Toda empresa debe contar con Reglamentos Internos, con la finalidad de mantener un régimen disciplinario y reconocimiento de deberes y derechos tanto de los trabajadores, como de los empleadores.

Los Reglamentos permiten cumplir con una selección de personal adecuada, describen los derechos, deberes y prohibiciones tanto de los empleadores, como de los trabajadores, dan lugar a cumplir legalmente con las tablas de sueldos y salarios, establecen sistemas de reconocimiento de 
promociones, medios de capacitación a sus integrantes para mejorar su desempeño y describen todos los aspectos en materia de seguridad industrial, entre otros.

Las decisiones que se derivan de procesos unilaterales pueden acarrear directamente, como resultado, un conflicto. Esto depende, por supuesto, del grado en el cual las normas sean consideradas justas.

Puede que el conflicto que surja como resultado del uso que una parte hace de su poder para imponerle normas a la otra no se exprese abiertamente (por ejemplo, cuando los empleados temen represalias de su empleador si se quejan sobre las condiciones en las que trabajan). Aunque dicho conflicto sea real, probablemente sea difícil de detectar porque la comunicación entre el empleador y los empleados es unidireccional. No obstante, probablemente se exprese en forma de desmotivación de los empleados, baja calidad del producto, alta tasa de rotación del personal, gran desperdicio de materias primas o incluso en diversas formas de sabotaje. El conflicto que no se expresa abiertamente se debe abordar mediante un cambio en el proceso de creación de normas: de uno basado en el "poder sobre" a uno que haga hincapié en compartir el poder.

$\mathrm{Si}$ el resultado de las interacciones es el conflicto, la discordia, el desacuerdo y las disputas, es necesario un cambio en los productos. Esto requiere, o bien distintas entradas (por ejemplo, cambio del entorno, cambio de valores), o distintos procesos (por ejemplo, cambio de un proceso unilateral a uno bilateral y, por ende, compartir más el poder) o un cambio tanto de entradas como de procesos.

La resolución de conflictos es indispensable en cualquier compañía, dado que los conflictos en periodos largos, pueden provocar problemas como desestabilización de la organización, y el mal desempeño de los trabajadores, lo cual se puede ver reflejado en la entrega de pedidos y el servicio inadecuado a los clientes, es por ello que los gerentes en la actualidad buscan crear espacios de mejora continua en lo que se refiere al clima organizacional; de esta manera prevenir los conflictos laborales y a su vez llevar a los trabajadores por un camino de eficiencia en su labor

Son muchos los factores de los que depende un buen ambiente de trabajo, pero uno de los motivos determinantes es cómo se resuelven los conflictos laborales, la forma en la que los abordamos.

Los conflictos son desencuentros que ocurren entre dos o más personas cuando la acción de una de ellas impide que la otra u otras personas alcancen lo que necesitan o dicha acción choca con sus valores u objetivos.

Los conflictos forman parte de la vida por lo que van a existir ineludiblemente en todos los ámbitos en las relaciones con otras personas: personal, de pareja, familiar, y por supuesto laboral.

Por tanto, una de las primeras cuestiones es aceptar que la posibilidad de tener conflictos es normal, y que debemos afrontarlos con una actitud de control y naturalidad. Si mantenemos ante un posible conflicto una actitud de amenaza, alarma o sorpresa, cuando se produzca nos sentiremos desbordados siempre y nos resultará más difícil afrontarlos.

Los conflictos son sin duda una fuente de estrés que a su vez favorece los conflictos. 
Este círculo vicioso se produce cuando una persona al estar estresada se vuelve más rígida y se centra en su punto de vista sin atender a otros, está más susceptible, por lo que su comunicación suele ser más agresiva y la posibilidad de cooperación y negociación disminuye. Se está más a la defensiva, la frustración favorece un trato incorrecto hacia los compañeros y compañeras y desde luego disminuye la capacidad de agradecimiento y refuerzo hacia ellos y ellas, muy importante en los trabajos en equipo.

El conflicto es una parte inevitable de la vida El conflicto es una parte inevitable de la vida organizacional. Un cierto grado de conflicto puede ser organizacional. Un cierto grado de conflicto puede ser beneficioso para la organizacional beneficioso para la organización los conflictos suelen tomar vida propia, cuando esto Los conflictos suelen tomar vida propia, cuando esto sucede la posibilidad de un resultado beneficioso queda sucede la posibilidad de un resultado beneficioso queda minimizada

Cuando se presta atención a aquellos procesos que $\mathrm{n}$ a aquellos procesos que pueden provocar que los conflictos se conviertan en pueden provocar que los conflictos se conviertan en destructivos, los conflictos pueden llegar a minimizarse, destructivos, los conflictos pueden llegar a minimizarse, resolverse y hasta a evitarse

Importante es tomar en cuenta que cuando se manifiesta un conflicto que ha dado paso a un ambiente, clima nefasto para la organización, de inmediato se debe analizar la causa que lo han generado, el porqué de su manifestación, las consecuencias, efectos y buscar de inmediato las soluciones que eviten que este no solamente conlleve a una situación negativa para la empresa, para el grupo, para el individuo, para su autoestima, su desempeño y sobre todo que no se vuelva a repetir.

\section{Conclusiones}

- Para evitar cualquier tipo de conflictos, es necesario mantener debidamente legalizada la empresa ante las autoridades competentes, contar cuando menos con los reglamentos de Administración de Talento Humano y de Seguridad Industrial.

- La Ley de Compañías, obliga a que en todo tipo de empresas, cuente con un Administrador Titular, el cual será el responsable directo de la gestión de la empresa, quien controlará el cumplimiento de las disposiciones internas descritas en los correspondientes reglamentos. Reglamentos que se sujetarán a las disposiciones dadas en la Ley de Compañías y Códigos de Trabaja, de Comercio y Penal, pues de esta manera, se evita problemas antes de que los mismos se degeneren en conflictos.

- Finalmente debemos tener presente que, un conflicto es en definitiva es un problema a causa de diferencias, controversias, litigios, es decir peleas, luchas por algún interés entre las personas que laboran al interior de una organización empresarial y que puede conllevar a agresiones verbales o físicas, y hasta el crimen. Desde el punto de vista jurídico conflicto por diferencias, controversias, colisiones, litigios, etcétera; todas ellas tienen invariablemente la connotación de pretensión resistida de oposición de intereses 
- El conflicto estimula el análisis crítico. no hay una situación más perjudicial para la organización que el no acatar las malas decisiones, el no prestarles atención. el atacar los planes, políticas y objetivos y el hacer que sus proponentes los defiendan estimula a las partes a examinar los temas con cuidado. En este sentido, el conflicto actúa como un disuasivo de la conformidad.

- El conflicto puede estimular un ambiente competitivo en donde todas las partes demuestran una voluntad de desarrollar un alto nivel de esfuerzo.

- El conflicto es un precursor de cambio. El cambio organizacional no es posible sin conflicto. El conflicto proporciona el desequilibrio inicial que estimula una búsqueda de alternativas. Aquellas personas que buscan el cambio en las organizaciones suelen por comenzar a construir coaliciones que representan conflictos con el estado de cosas.

- Muchos conflictos son resueltos por las partes mismas a través de procesos de diálogo basados en el consenso, de negociación y convenios.

- Cuando los convenios y la negociación fracasan y se llega a un punto muerto, se tornan necesarias las intervenciones de terceros que ayuden a las partes en disputa a resolver el conflicto. Algunas intervenciones, como la conciliación mediación, aún se basan en el consenso, pero otras, concretamente el arbitraje y la resolución judicial, involucran a terceros que decidirán cómo se dirimirá el conflicto.

- Los conflictos son una parte estrecha de la existencia del hombre, en su vida cuando el hombre se relaciona con otros hombres y con la sociedad

- El conflicto es una situación inherente al ser humano como "animal social", le es consustancial como miembro de un grupo social. El conflicto se puede dar en el contexto de diferentes puntos de vista, de diferentes objetivos e intereses o de una socialización, de una historia personal, de un aprendizaje y de unas experiencias vividas personal y colectivamente que son diversas. En este entramado de las complejas relaciones grupales, el conflicto aparece de manera social ("natural" como especie humana). No se trata de negarlo, sino de transformarlo y considerarlo como una oportunidad de mejora. La gestión del conflicto podrá determinar si éste finalmente puede ser vivido como positivo, y si ha contribuido al desarrollo y enriquecimiento del grupo y de sus relaciones interpersonales.

- En este sentido, y destacando la idea de la resolución de conflictos en su objetivo de cambio, desarrollo enriquecedor y evolución grupal, las relaciones y los conflictos deben ser tratados, ordinariamente, como situaciones intergrupales, resaltando aquello que dé común se tiene en el grupo. La cohesión interna debe ser fundamentada sobre unos grandes objetivos compartidos, unas líneas generales que enmarquen ampliamente la vida del grupo y su devenir cotidiano. No se debe caer en la aporía de la dinámica intergrupal, ni especular con las posibilidades de un enfrentamiento entre subgrupos, creyendo que el nuestro se va a cohesionar positivamente, permitiendo con ello afianzar un liderazgo indiscutible que beneficie los intereses de unos pocos y no de todos. La cohesión grupal que se genera o se potencia por la vinculación propia frente a otro grupo diferente, fortaleciendo el conflicto intergrupal, falla en la base, porque se fortalece como grupo a través de dicha conflictividad. ampliamos la idea de que esta situación está conformando una "identidad de resistencia" que cohesiona al nosotros, resistiendo contra los otros. Esta situación debe enriquecerse positivamente, vehiculándose a través de la "identidad proyecto", argumentándose en lo común, en la amplitud de miras y en el compartimiento y la 
ISSN: 2600-5859

participación de todos los integrantes del grupo. Si bien colaborar y compartir pueden generar conflicto, la confianza y la consolidación de las relaciones, a través de la empatía, debe dar pie a la transformación del conflicto, haciendo de éste una oportunidad de mejora y de verdadera cohesión grupal.

\section{Referencias Bibliográficas}

Estado Ecuatoriano. (2012). Código de Trabajo. Quito: Registro Oficial 167.

Comisión Económica para América Latina . (2009). Manual de Planificación Estratégica. Recuperado el 15 de febrero de 2019, de Planificación Estratégica: https://www.cepal.org/ilpes/noticias/paginas/3/38453/manual_planificacion_estrategica.p df

Dirección de Talento Humano. (diciembre de 2013). Manual de Descripción, Valoración y Clasificación de Puestos. Recuperado el 15 de marzo de 2019, de https://www.controlsanitario.gob.ec/wp-content/uploads/downloads/2014/04/Manual-deDescripci\%C3\%B3n.pdf

Estado Ecuatoriano . (2014). Código Orgánico Integral Penal. Quito: Registro Oficial Organo del Gobierno del Ecuador.

Estado Ecuatoriano Consejería de Educación. (9 de septiembre de 2008). Cualificación Profesional de Operario de Carpintería. Recuperado el 2 de febrero de 2019, de Descripción de funciones.

Estado Ecuatoriano. (10 de enero de 2008). Reglamento de Seguridad y Salud. Recuperado el 5 de marzo de 2019, de http://www.trabajo.gob.ec/wpcontent/uploads/downloads/2012/12/Reglamento-de-Seguridad-y-Salud-para-laConstrucci\%C3\%B3n-y-Obras-P\%C3\%BAblicas.pdf

Estado Ecuatoriano Consejo de Participacion Ciudadana . (7 de marzo de 2017). Reglamento Interno de Adminbistración de Talento Humano. Recuperado el 12 de marzo de 2019, de https://www.defensa.gob.ec/wp-content/uploads/downloads/2017/08/CPCCS.pdf

Estado Ecuatoriano Oficina Nacional de Personal . (8 de diciembre de 1999). Descripción de funciones. Manual de Personal. Quito, Pichincha, Ecuador: Gobierno Nacional.

Estado Ecuatoriano Registro Oficial. (2017). Ley de Compañías. Quito: Registro Ofiicial Gobierno del Ecuador . 
Estado Ecuatoriano, Ministerio de Turismo. (2016). Reglamento de Talento Humano. Recuperado el 10 de marzo de 2019, de https://www.turismo.gob.ec/wpcontent/uploads/2016/10/Acuerdo-Ministerial-No-2016-036.pdf

Estado Ecuatoriano, Ministero de Relaciones Laborales. (2012). Manual de Descripción, Valoración y Clasificación de los Puestos. Recuperado el 15 de marzo de 2019, de http://www.trabajo.gob.ec/wp-content/uploads/downloads/2012/10/R-0472-2012MINISTERIO-DE-COORDINACION-POLITICA.pdf

Jorge, L. (octubre de 2016). Conceptos de planificación estratégica. Recuperado el 18 de febrero de 2019, de http://200.40.96.180/images/conceptos_y_vinculo_cg.pdf

LEXIS. (23 de octubre de 2014). Reglamento para la Administración de Talento Humano.

Recuperado el 10 de marzo de 2019, de http://www.evaluacion.gob.ec/wpcontent/uploads/downloads/2015/08/Resolucion-48-Administracion-de-talentohumano.pdf

Organización Internacional del Trabajo. (2013). Sistemas de Resolución de Conflictos Laborales. Recuperado el 22 de febrero de 2019, de https://www.ilo.org/wcmsp5/groups/public/--ed_dialogue/---dialogue/documents/publication/wcms_337941.pdf

Pacheco Mena, M., \& Zapata López, J. (2014). Técnicas de resolución a conflictos. Latacunga Ecuador: Universidad Técnica de Cotopaxi.

Pimentel Villalaz, L. (Septiembre de 1999). Planificación Estratégica. Recuperado el 4 de febrero de 2019, de http://www.unipamplona.edu.co/unipamplona/portalIG/home_4/mod_virtuales/modulo5/ 5.2.pdf

RUTA. (2003). Planificación Estratégica. Recuperado el 22 de febrero de 2019, de http://unpan1.un.org/intradoc/groups/public/documents/icap/unpan030136.pdf

Scott, A. (2013). Planificación Estratégica. Edinburgo: EDINBURGH.

Toro Culcay, C. E. (3 de enero de 2018). Propuesta para el manejo de conflictos laborales . Recuperado el 3 de marzo de 2019, de http://repositorio.uasb.edu.ec/bitstream/10644/6151/1/T2581-MDTH-Toro-Propuesta.pdf

UNAM. (1980). Conflicto Laboral. México DF: Instituto de Investigaciones Jurídicas de la UNAM. 
Para citar el artículo indexado

Ibarra Chango, M. del C., Vallejo Villalva, M. del P., \& Arias González, I. P. (2020). Conflictos laborales en las empresas comerciales e industriales en el Ecuador. ConcienciaDigital, 3(1.1), 314-333. https://doi.org/10.33262/concienciadigital.v3i1.1.1151

El artículo que se publica es de exclusiva responsabilidad de los autores y no necesariamente reflejan el pensamiento de la Revista Conciencia Digital.

El articulo queda en propiedad de la revista y, por tanto, su publicación parcial y/o total en otro medio tiene que ser autorizado por el director de la Revista Conciencia Digital.

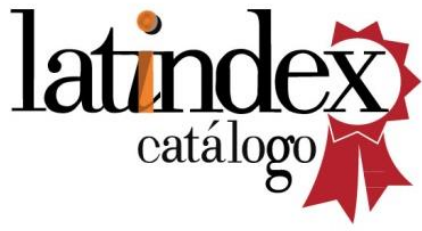

\section{Conciencia}

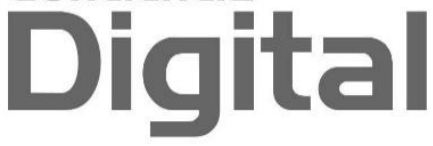

